\title{
Treatment Modalities for Post Corrosive Esophageal Strictures: 5 Years Experience
}

\author{
Mohamed Abdelshafy Mohamed', Hasan Sedeek Mahmoud², Mohammed Tag-Adeen³ \\ ${ }^{1}$ Department of General Surgery, Faculty of Medicine, South Valley University, Qena, Egypt \\ ${ }^{2}$ Department of Tropical Medicine and Gastroenterology, Faculty of Medicine, South Valley University, Qena, Egypt \\ ${ }^{3}$ Department of Internal Medicine, Faculty of Medicine, South Valley University, Qena, Egypt \\ Email: hasan_sedeek@yahoo.com
}

How to cite this paper: Mohamed, M.A., Mahmoud, H.S. and Tag-Adeen, M. (2018) Treatment Modalities for Post Corrosive Esophageal Strictures: 5 Years Experience. Open Journal of Gastroenterology, 8, 394-404. https://doi.org/10.4236/ojgas.2018.811041

Received: October 9, 2018

Accepted: November 2, 2018

Published: November 5, 2018

Copyright (C) 2018 by authors and Scientific Research Publishing Inc. This work is licensed under the Creative Commons Attribution International License (CC BY 4.0).

http://creativecommons.org/licenses/by/4.0/

(c) (i) Open Access

\begin{abstract}
Background: Management of post-corrosive esophageal strictures represents a major challenge for clinicians. There are many options for treatment as dilatation alone or dilatation with injection of corticosteroids, stent placement, and surgery. The aims of the study: This is a retrospective study to assess the success rate of different treatment modalities for post-corrosive esophageal stricture including: endoscopic dilatation, stenting or surgery and to define any complications. Methods: Clinical and endoscopic data for patients with post-corrosive esophageal stricture admitted to the endoscopy unit between September 2012 and September 2017 were collected. Retrospective analysis of data was done to detect the types of treatment, success rate and any detectable complications. Results: A total of 50 patients with their ages ranged between 3 and 20 years were included in this study. Male patients represented 54\% (27 patients) and females were 23 (46\%). The cause of caustic material ingestion was mainly accidental (47 patients, 94\%) and only 3 patients were suicidal (6\%). Dilatation was successful in most cases either with or without injection of corticosteroids (39 patients, 78\%). Stenting was a good option in cases of refractory or recurrent dilatations (11 patients; $22 \%$ ) with excellent results. Surgery rarely needed (only in one patient) and only when dilatation and stenting failed. Conclusions: Endoscopic treatment of post-corrosive esophageal stricture has a good result and low rate of complications. The covered self-expandable metal stent (SEMS) is a good option in cases of refractory strictures, surgery rarely needed and after failure of previous modalities.
\end{abstract}

\section{Keywords}

Post-Corrosive Esophageal Stricture, Caustic Ingestion, Endoscopic Treatment 


\section{Introduction}

Corrosive ingestion is the most common cause of esophageal strictures in children and young adult leads to a progressive and devastating injury to the esophagus and stomach. Injury to the esophageal wall results in thickening of its layers which lastly heal by fibrosis [1] [2] and frequently encountered in children who accidentally swallowed caustic materials or in adults for suicidal purposes [3] [4].

Alkaline caustics and acids are the most chemicals that involved in the esophageal burn that lead to stricture formation and the inability to swallow food after the injury. High-alkaline cleaners are predominately found in oven cleaners and drain cleaning solutions. Acids like hydrochloric and sulfuric acid are used in many industries such as fertilizer, detergent, and automotive batteries. Alkali ingestion is more common than acid with an overall ratio of 8:1 respectively [4].

The most common causes of post-corrosive esophageal strictures in Egypt are ingestion of caustic potash. The concentration and amount of the ingested material and the time of contact with the mucosa, have an important impact on the injury [5]. Esophageal Strictures formation occurs in 3\% to $57 \%$ of ingestions with documented esophageal burns. Most of them are third-degree (circumferential) burns that lead to esophageal strictures, regardless of treatment. Comparatively, $80 \%$ of cases who develop a stricture will have a dysphagia within two months and may be earlier in more severe injury [6] [7].

Dysphagia is the main presenting complaint in patients with post corrosive esophageal strictures and occurs within 1 to 2 months. The presence of other symptoms as early satiety, loss of weight, and progressive vomiting suggest gastric outlet obstruction. Repeated chest infections may indicate acquired tracheo-esophageal stricture [5]. Weight loss may be present but not so marked as in malignant strictures.

The aim of the treatment of esophageal strictures is to relief dysphagia and to prevent recurrent esophageal narrowing and improve quality of life.

There are many options for treatment as endoscopic dilatation, alone or with injections of corticosteroids and removable self-expanding intra-luminal stents, and surgery. The first line is endoscopic dilatations as it is feasible to use and offers great relief of dysphagia with low rates of complications [8], but unfortunately, more than a third of patients are still complaining after dilatation and need more sessions [9].

In order to decrease the time and encumbrance of endoscopic dilatations to relief symptoms of dysphagia, varies endoscopic treatment can be used. Using steroid injection alongside endoscopic dilatation into the stricture segment followed by dilatation could prevent the recurrence of stricture and dysphagia. In the last few years, placement of temporary stent has been used widely for refractory post-corrosive esophageal strictures. Self-Expandable plastic stents (SEPS) are FDA approved to be used in such cases [10].

Surgical treatment as Esophagectomy with gastric or intestinal interposition 
for reconstruction has high morbidity rate and uncertain results in the long run, so it is indicated in severe cases that are unresponsive to endoscopic dilatation [11] [12] [13] [14]. So, there are quite controversies regarding the plan of treatment and many different therapies have been recommended.

Chronic patients need repeated dilatations to keep an adequate lumen diameter. As regards more severe strictures, because of the failure of dilatation and the presence of complications, surgical replacement of the esophagus may be required.

The aims of this study: to assess the success rate of different treatment modalities for post-corrosive esophageal stricture including; endoscopic dilatation, stenting or surgery and to define the occurrence of any detectable complications.

\section{Patients and Methods}

\subsection{Patients}

The current study is a retrospective one included data of 50 patients with post corrosive esophageal stricture admitted to the endoscopy unit between September 2012 and September 2017. This study was conducted in the GIT endoscopy unit in Qena University Hospitals in collaboration with General surgery, Tropical Medicine and Gastroenterology and Internal Medicine departments. All data of the history taking, clinical examination and radiological examination of the esophagus were collected.

Informed consent was obtained from all patients or their parents in case of children and adolescents to include in this study after explanations of the nature of the disease and possible treatment options whether alone or with injection of triamcinolone or stent placement. The written consent form was signed before the procedure.

\subsection{Ethical Approval}

The current study was approved by our local faculty ethical committee.

\subsection{Methods}

The examination was done under general anesthesia with airway protection. Olympus, GIF-XQ260 instrument was used for doing upper endoscopic examination. During esophagoscopy different parameters were evaluated to facilitate the choice of the most applicable dilator. Those parameters included the site, the diameter, and the macroscopic picture of the stricture. All these data were collected.

\subsection{The Procedures}

After diagnostic upper endoscopy was done the following treatment modalities were chosen accordingly:

1) Esophageal dilatation only: The guide wire was inserted under endoscopic control and fluoroscopy guide. Savary-Gilliard dilators semiflexible bougie was 
introduced starting from smaller to larger diameter. We started with three dilators per session, with progressively increasing diameters. Patients were managed on a stepwise basis, and we used the anatomy of the esophagus to determine the technique and the type of dilator which should be employed. Dilatation sessions were run at an average interval of 15 days.

2) Esophageal dilatation and triamcinolone injection: After full dilatation of the esophagus; until reaching more than $14 \mathrm{~mm}$ in diameter, triamcinolone injection was done. We used sclerotherapy injection needle (23-gauge \& $5 \mathrm{~mm}$ long) for intra-lesional triamcinolone injection (triamcinolone acetate $10 \mathrm{mg} / \mathrm{mL}$ with $0.5 \mathrm{~mL}$ volume per injection). The esophagus was divided into four quadrants and four to six injections were done at the upper part of the stricture area followed by another four to six injections into the stricture proper site. Dilation session was made after injections.

3) Esophageal Stenting: This procedure was done in cases of recurrent (recurrence within 4 week) and refractory strictures (esophageal dilatation more than five sessions 2-week interval). Strictures fully covered SEMS Wallflex (Boston Scientific, Natick, MA) was introduced through guide wire under endoscopic view and fluoroscopy control. Patients kept under observation at the GIT endoscopy unit for 2 to 3 hours. Follow up endoscopy was done 2 weeks and four weeks later to ensure stent in place. Stent removal was done after 6 - 8 weeks.

4) Surgery: Esophagectomy with transit reconstruction in case of failure of previous modalities

\section{- Out-patient follow up:}

The cases were followed in the outpatient clinics every month for recurrence of dysphagia and the follow up period ranged from 12 to 24 months. Relief of symptoms and gain of body weight were used as clinical parameters to evaluate the response to endoscopic dilatation, as well as the interval between sessions. Those patients who did not need endoscopic dilatation for 6 months were discharged.

\subsection{Statistical Analysis}

the statistical analysis of data was done by using IBM SPSS (ver. 20.0) computer software for Statistical analysis under Microsoft window 10. For all statistical analysis, $\mathrm{p}<0.05$ was considered significant.

\section{Results}

\subsection{Demographic Data}

50 patients were included in the current study with their ages ranged between 3 and 20 years; most of them were below 10 years. Males were 27 patients; representing 54\% and females were 23 (46\%) (Table 1).

Most of our cases were ingested caustic materials (caustic potash) accidently in 47 patients (94\%) and only 3 patients (6\%) were for suicidal purposes (one male and two females) (Table 2). 
Table 1. Demographic data for included patients.

\begin{tabular}{cc}
\hline Parameters & $(\mathbf{n}=\mathbf{5 0 ) \%}$ \\
\hline$\underline{\text { Age, range (years) }}$ & $3-20$ \\
$\underline{\text { Gender }}$ & \\
Male & $27(54 \%)$ \\
Female & $23(46 \%)$
\end{tabular}

Data expressed as number, \%.

Table 2. Cause of corrosive ingestion.

\begin{tabular}{cc}
\hline Causes & $(\mathrm{n}=\mathbf{5 0}) \%$ \\
\hline Accidental & $47(94 \%)$ \\
Suicidal & $3(6 \%)$ \\
\hline
\end{tabular}

Data expressed as number, \%.

\subsection{Endoscopic Assessment for Esophageal Stricture}

As regard the location of the stricture, 9 patients (18\%) showed upper-third stricture, $5(10 \%)$ were mid-third, $6(12 \%)$ were lower-third and most of cases; $30(60 \%)$ were multiple strictures. The stricture was simple in 15 patients $(30 \%)$ and complex in 35 patients (70\%) (Table 3 ).

\subsection{Successful Treatment Modalities}

Dilatation alone was successful in 34 patients $(68 \%)$ and 5 patients (10\%) treated with dilatation and injection of triamcinolone. 11 patients (22\%) needed dilatation and stent placement and only one patient treated surgically due to failed previous modalities (Table 4) (Figures 1-3).

\subsection{Complications of Endoscopic Dilatation and Stenting}

Minor bleeding which was non-significant occurred during dilatation in 7 patients (14\%). Retrosternal pain after stent placement was encountered in 4 patients, stent migration in 2 patients and minor upper GIT bleeding in 2 patients with stent placement (Table 5).

\section{Discussion}

Caustic ingestion is seen most frequently in young kids between 1 - 3 years older, with boys accounting for $50 \%$ to $62 \%$ of patients. Alkaline agents (mostly household bleaches) were more commonly ingested than were acids. Other products most often involved included automatic dishwasher agents, laundry detergents, swimming pool products, and toilet and oven cleaner. Esophageal burns due to ingestion of caustic materials were detected in $18 \%$ to $46 \%$ of children [15].

The most common causes of post-corrosive esophageal strictures in Egypt are due to caustic potash. The concentration and amount of the ingested material 
Table 3. Location and type of esophageal stricture in all patients.

\begin{tabular}{cc}
\hline Parameters & Number of patients $\mathrm{n}=\%$ \\
\hline Location of strictures: & $9(18 \%)$ \\
\hline Upper-third & $5(10 \%)$ \\
Mid-third & $6(12 \%)$ \\
Lower-third & $30(60 \%)$ \\
Multiple & \\
\hline Types of stricture: & $15(30 \%)$ \\
\hline Simple & $35(70)$ \\
\hline Complex &
\end{tabular}

Data expressed as number, \%.

Table 4. Different endoscopic treatment modalities used in all patients.

\begin{tabular}{lc}
\hline \multicolumn{1}{c}{ Modalities of treatment used } & Number of patients $\mathbf{n}=\%$ \\
\hline - Dilations alone & $34(68 \%)$ \\
- Dilation and injection of triamcinolone & $5(10 \%)$ \\
- Dilation and stent placement & $11(22 \%)$ \\
- Surgery & $1(2 \%)$ \\
\hline
\end{tabular}

Data expressed as number, \%.

Table 5. Complications of endoscopic dilatation and stenting in all patients.

\begin{tabular}{|c|c|}
\hline Complications detected & Number of patients $n=\%$ \\
\hline \multicolumn{2}{|l|}{ Complications of dilatation: } \\
\hline - Minor bleeding & $7(14 \%)$ \\
\hline - Major bleeding & 0 \\
\hline - Perforation & 0 \\
\hline - Aspiration & 0 \\
\hline \multicolumn{2}{|c|}{ Stent complication (stent patients $=11$ ) } \\
\hline - Retrosternal pain & $4(36 \%)$ \\
\hline - Hiccough & 0 \\
\hline - Stent migration & $2(18 \%)$ \\
\hline - Major Upper GI bleeding & 0 \\
\hline - Minor Upper GI bleeding & $2(18 \%)$ \\
\hline - Perforation & 0 \\
\hline - Aspiration & 0 \\
\hline - Respiratory arrest & 0 \\
\hline - Tracheal compression & 0 \\
\hline - Death due to the procedure & 0 \\
\hline
\end{tabular}

Data expressed as number, \%. 


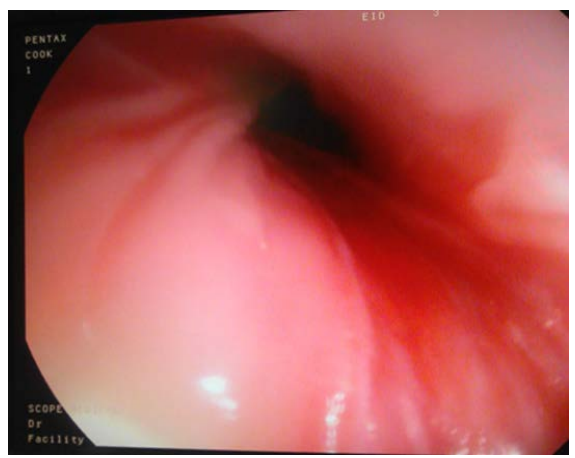

(a)

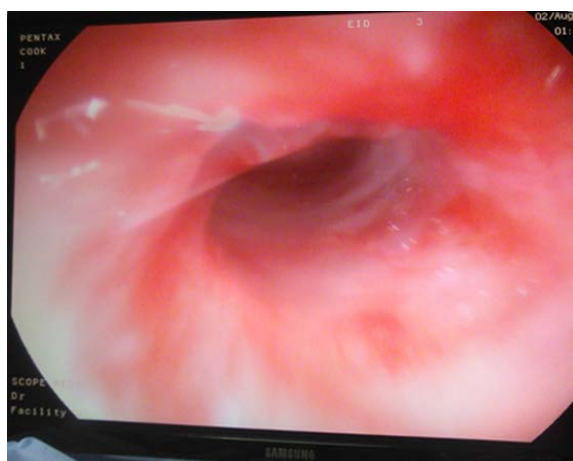

(b)

Figure 1. Endoscopic view for post-corrosive esophageal stricture before intervention, Qena University Hospital, GIT Endoscopy unit, South Valley University.

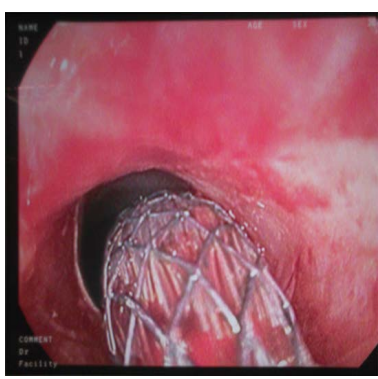

(a)

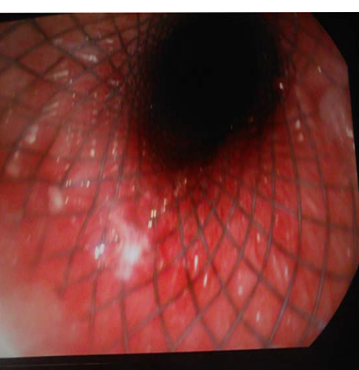

(b)

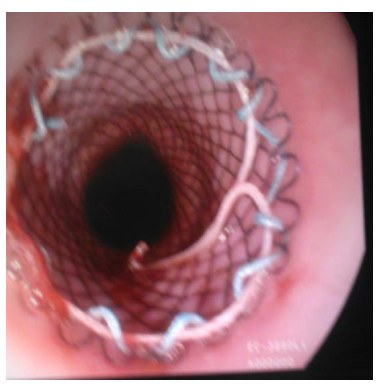

(c)

Figure 2. Esophageal stent placement for post-corrosive stricture.

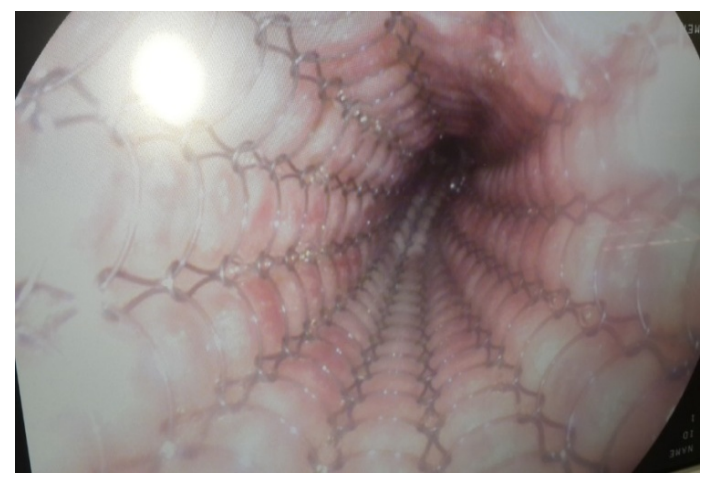

Figure 3. Endoscopic view of esophageal stent 4 weeks after insertion.

and the length of time the agent remains in contact with the mucosa, have an important impact on the injury [5]. The severity of damage and the extension to the gastrointestinal tract depends on many factors including the type of agent, its concentration, physical state and the time of exposure. Two factors affecting the chance and the degree of penetration: the concentration and the length of time the agent remains in contact with the mucosa. The most severe caustic injury generally occurs in the narrowest portion of the oesophagus, usually the mid-oesophagus in the region of the aortic arch [5] [16] [17]. 
Corrosive esophageal strictures tend to be multi-segmented, rigid, tortuous, more extensive, being technically difficult to dilate, and with a higher rate of recurrence compared to esophageal obstructions of other causes [11] [18] [19]. The need to repeat endoscopic dilatation sessions and the low rate of discharge confirm that fact and will be confirmed if compared to patients with other types of strictures.

The first step in managing post-corrosive esophageal strictures remains with an Inflatable balloon or a (Savary) bougie [3] [18]. According to Cox J G et al. [20] and Yamamoto $\mathrm{H}$ et al. [21], there is no difference are shown between balloon and bougie in relief of dysphagia and/or return of disorder and no variations are shown within the risk of major complications like perforation, bleeding, and bacteremia. Moreover, the literature shows no important distinction between wire-guided dilators and polyurethane balloons in terms of affectivity and rate of complications [22]. Although most of the cases are completely treated with up to 5 sessions, about $10 \%$ of cases need furthermore sessions to be free of symptoms [5] [22].

In our study, we retrospectively reviewed 50 patients with post-corrosive esophageal strictures from September 2012 and September 2017. Most of patients were under the age of 10 years and this explained that the most common cause is accidental ingestion in young children, only in three patients, the cause was suicidal and in older ages (one male and two females).

Our treatment strategy was to start with dilatation alone if failure occurred we used dilatation with injection of triamcinolone. If recurrence or refractory case we shifted to stent insertion and lastly if failed we proceeded to surgery. Dilatation was efficient in most cases with or without injection. Only 11 cases were refractory and treated by stent insertion which was successful except one case that needed surgery.

The optimal diameter of the esophageal lumen after dilatation is obtained by the patient's clinical conditions, considering the progress of dysphagia and/or nutritional status, and weight gain, Also an examination of the esophageal mucous membrane [1] [15]. Esophageal perforation is a fatal complication of endoscopic dilatation, with an incidence of $0.7 \%$ to $3.5 \%$ and is always regarded as a severe clinical condition [23]. In the current study, esophageal perforation, as a complication of dilatation was not encountered.

The intra-lesional injection of corticosteroids (triamcinolone) in more complex esophageal strictures has been highlighted in the literature. Its use is based on the reduction of inflammatory response, fibrosis, and the development of re-stenosis after dilatations, observed by the relief of symptoms, preservations of esophageal diameter during the session and prolongs the time between endoscopy sessions. However, the results are still heterogeneous and therefore the procedure isn't perpetually spare to stay the patency of the esophageal lumen [2].

A randomized trial was performed to evaluate endoscopic dilatation with an injection of intra-lesional steroids and they concluded that dilatation with steroid injection therapy decreased the number of repeated sessions and also the 
dysphagia free period [24].

The rapid evolution of self-expanding and removable plastic stents allowed for a new treatment of strictures, with the benefit of decreasing numbers of dilatation sessions and keeping the esophagus patent for a long time, without the complications that usually associated with metal stents [25].

A recent report published by Ham, et al., the study was conducted on 172 cases with a benign esophageal stricture and treated with self-expandable stents (SEPS), they reported a technical success rate of $98 \%$ and a clinical success rate of $45 \%$ with a rate of stent migration of $31 \%$ and concluded that SEPS are effective for the treatment of refractory esophageal strictures but the study needs more improvement to decrease the risk of early migration. Moreover, the stent has a high radial and axial force that may increase the risk of stent-related complications to the esophageal wall, such as severe bleeding [26].

\section{Conclusion}

This study concluded that the endoscopic dilatation for post corrosive esophageal strictures remains the best option with satisfactory results and lower complications rate in spite of repeated sessions. Stent placement after repeated sessions in non responder is the second treatment modality of choice. Prevention is still the best treatment against post corrosive esophageal strictures through awareness and safe storage of corrosive substances.

\section{Conflicts of Interest}

All authors confirmed that there is no conflict of interest.

\section{References}

[1] Poddar, U. and Thapa, B.R. (2001) Benign Esophageal Strictures in Infants and Children: Results of Savary-Gilliard Bougie in 107 Indian Children. Gastrointestinal Endoscopy, 4, 480. https://doi.org/10.1067/mge.2001.118253

[2] Broor, S.L., Lahoti, D., Bose, P.P., Ramesh, G.N., Raju, G.S. and Kumar, A. (1996) Benign Esophageal Strictures in Children and Adolescents. Etiology, Clinical Profile, and Results of Endoscopic. Gastrointestinal Endoscopy, 7, 474. https://doi.org/10.1016/S0016-5107(96)70289-4

[3] Havanond, C. (2003) Clinical Features of Corrosive Ingestion. Journal of the Medical Association of Thailand, 86, 918-924.

[4] Rodriguez, M.A. and Meza-Flores, J.L. (2003) Clinical-Epidemiological Characteristics in Caustics Ingestion Patients in the Hipolito Unanue National Hospital. Revista De Gastroenterologia Del Peru, 23, 115-125.

[5] Mattos, G.M., Lopes, D.D., Mamede, R.C.M., et al. (2006) Effects of Time of Contact and Concentration of Caustic Agent on Generation of Injuries. Laryngoscope, 116, 456-460. https://doi.org/10.1097/01.mlg.0000199935.74009.60

[6] Moazam, F., Talbert, J.L., Miller, D., et al. (1987) Caustic Ingestion and Its Sequelae in Children. Southern Medical Journal, 80, 187-190. https://doi.org/10.1097/00007611-198702000-00012

[7] Gaudreault, P., Parent, M., McGuigan, M., Chicoine, L. and Lovejoy, F. (1983) Pre- 
dictability of Esophageal Injury from Signs and Symptoms: A Study of Caustic Ingestion in 378 Children. Pediatrics, 71, 767-670.

[8] Hirdes, M.M., Vleggaar, F.P. and Siersema, P.D. (2011) Stent Placement for Esophageal Strictures: An Update. Expert Review of Medical Devices, 8, 733-755.

https://doi.org/10.1586/erd.11.44

[9] Siersema, P.D. (2008) Treatment Options for Esophageal Strictures. Nature Clinical practice. Gastroenterology \& Hepatology, 5, 142-152. https://doi.org/10.1038/ncpgasthep1053

[10] Wadhwa, R.P., Kozarek, R.A., France, R.E., et al. (2003) Use of Self-Expandable Metallic Stents in Benign GI Diseases. Gastrointestinal Endoscopy, 58, 207-212. https://doi.org/10.1067/mge.2003.343

[11] Ferreira, C.T., Pretto, F.M., Angeli. C., Nunes, D.A., Zim, M.C., CantaliceNeto, A., et al. (2003) Estenose de esôfagonacriança: etiologia, aspectosclínicos e resultados de dilatações com Savary-Gilliard. GED, 22, 61-67.

[12] Mutaf, O. (1992) Esophagoplasty for Caustic Esophageal Burns in Children. Pediatric Surgery International, 7, 106-108. https://doi.org/10.1007/BF00183913

[13] Loeb-Abram, P.M. and Eisenstein, M. (1998) Caustic Injury to the Upper Gastrointestinal Tract. In: Sleisenger and Fordtran's Gastrointestinal and Liver Disease, 6th Edition, W. B. Saunders Company, Philadelphia, 335-342.

[14] Riley, S.A. and Attwood, S.E.A. (2004) Guidelines on the Use of Oesophageal Dilatation in Clinical Practice. Gut, 53, i1-6. https://doi.org/10.1136/gut.53.suppl_1.i1

[15] Guitron, A., Adalid, R., Nares, J., Mena, G., Gutierrez, J.A. and Olivares, C. (1999) Benign Esophageal Strictures in Toddlers and Pre-School Children, Results of Endoscopic Dilation. Revista de Gastroenterología de México, 64, 12-15.

[16] Peters, J.H. and Demeester, T.R. (1999) Esophagus and Diaphragmatic Hernia. In: Schwartz, S.T., Shires, G.T., Spencer, F.C., et al., Eds. Principles of Surgery, 7th Edition, McGraw Hill, New York City, 1158-1161.

[17] Makela, J.T., Laitine, S. and Salo, J.A. (1998) Corrosion Injury of the Upper Gastrointestinal Tract after Swallowing Strong Alkali. European Journal of Surgery, 164, 575-580. https://doi.org/10.1080/110241598750005660

[18] Broto, J., Asensio, M. and Vernet, J.M.G. (2003) Results of a New Technique in the Treatment of Severe Esophageal Stenosis in Children: Poliflex Stents. Journal of Pediatric Gastroenterology and Nutrition, 37, 203-206. https://doi.org/10.1097/00005176-200308000-00024

[19] Kim, I., Yeon, K.M., Kim, W.S., Park, K.W., Kim, J.H. and Han, M.C. (1993) Perforation Complicating Balloon of Esophageal Strictures in Infants and Children. Radiology, 189, 741-744. https://doi.org/10.1148/radiology.189.3.8234699

[20] Cox, J.G., Winter, R.K., Maslin, S.C., et al. (1988) Balloon or Bougie for Dilatation of Benign Oesophageal Stricture? An Interim Report of a Randomized Controlled Trial. Gut, 29, 1741-1747. https://doi.org/10.1136/gut.29.12.1741

[21] Yamamoto, H., Hughes Jr., RW., Schroeder, K.W., Viggiano, T.R. and DiMagno, E.P. (1992) Treatment of Benign Esophageal Stricture by Eder-Puestow or Balloon Dilators: A Comparison between Randomized and Prospective Non-Randomized Trials. Mayo Clinic Proceedings, 67, 228-236. https://doi.org/10.1016/S0025-6196(12)60097-4

[22] Said, M., Mekki, M., Golli. M., Memmi, F., Hafsa, C., Braham, R., et al. (2003) Balloon Dilatation of Anastomotic Strictures Secondary to Surgical Repair of Oesophageal Atresia. The British Journal of Radiology, 76, 26-31. https://doi.org/10.1259/bjr/64412147 
[23] Martinez, L., Rivas, S., Hernandez, F., Avila, L.F., Lassaletta, L., Murcia, J., et al. (2003) Aggressive Conservative Treatment of Esophageal Perforations in Children. Journal of Pediatric Surgery, 38, 685-689. https://doi.org/10.1016/jpsu.2003.50183

[24] Ramage Jr., J.I., Rumalla, A., Baron, T.H., et al. (2005) A Prospective, Randomized, Double-Blind, Placebo-Controlled Trial of Endoscopic Steroid Injection Therapy for Esophageal Peptic Strictures. American Journal of Gastroenterology, 100, 2419-2425. https://doi.org/10.1111/j.1572-0241.2005.00331.x

[25] Repici, A., Conio, M., De Angelis, C., Battaglia, E., Musso, A., Pellicano, R., et al. (2004) Temporary Placement of an Expandable Polyester Silicone-Covered Stent for Treatment of Refractory Benign Esophageal Strictures. Gastrointestinal Endoscopy, 60, 513-519. https://doi.org/10.1016/S0016-5107(04)01882-6

[26] Ham, Y.H. and Kim, G.H. (2014) Plastic and Biodegradable Stents for Complex and Refractory Benign Esophageal Strictures. Clinical Endoscopy, 47, 295-300. https://doi.org/10.5946/ce.2014.47.4.295 